\title{
RESPONS FISIOLOGIS DAN ANATOMI AKAR TANAMAN BAYAM (Amaranthus tricolor L.) TERHADAP CEKAMAN NaCl
}

\section{(PHYSIOLOGICAL ResponsE AND ANATOMY OF ROOTY PLANT I Amaranthus tricolor L.J AGAINST NaCl)}

\author{
Ian Prabowo dan Diah Rachmawati \\ Fakultas Biologi Universitas Gadjah Mada \\ Bulaksumur Caturtunggal Depok Sleman Daerah Istimewa Yogyakarta 55281 \\ email: prabowoiaaan@gmail.com
}

\begin{abstract}
Abstrak
Tujuan dari penelitian ini untuk mengetahui pengaruh cekaman $\mathrm{NaCl}$ terhadap pertumbuhan dan anatomi akar tanaman bayam serta mengetahui konsentrasi $\mathrm{NaCl}$ yang dapat menghambat pertumbuhan tanaman bayam. Penelitian ini digunakan perlakuan $\mathrm{NaCl}$ sebanyak 0, 200, 400, 600 dan $800 \mathrm{mM}$ pada tanaman bayam (Amaranthus tricolor L.), Media tanam berupa campuran tanah dan pupuk kandang dan alkohol, safranin, aseton. Alat yang digunakan adalah med line, cawan poerslen, spektrofotometer dan mikroskop. Parameter yang diukur meliputi tinggi tanaman, jumlah daun, warna daun, panjang akar, jumlah akar, berat basah, berat kering, kadar klorofil, tebal epidermis akar, tebal korteks akar dan diameter stele akar. Data dianalisis dengan uji ANOVA dilanjutkan dengan DMRT taraf kepercayaan 95\% menggunakan program SPSS 15. Hasil yang diperoleh menunjukkan penambahan $\mathrm{NaCl}$ menyebabkan penurunan pertumbuhan tanaman bayam meliputi tinggi tanaman, jumlah daun, kadar klorofil, rasio tajuk dibanding akar dan menurunkan diameter stele akar. Pertumbuhan tanaman menurun seiring peningkatan konsentrasi $\mathrm{NaCl}$ karena $\mathrm{NaCl}$ menyebabkan cekaman osmotik yang menghambat penyerapan air dan unsur hara yang diperlukan tanaman untuk proses metabolisme.
\end{abstract}

Kata kunci: Amaranthus tricolor, $\mathrm{NaCl}$, pertumbuhan, akar

\begin{abstract}
The study was aimed at determining the effect of $\mathrm{NaCl}$ stress on the growth and anatomy of spinach roots and the concentration of $\mathrm{NaCl}$ which can inhibit the growth of spinach plants. This study used 0, 200, 400, 600 and $800 \mathrm{mM} \mathrm{NaCl}$ treatments on spinach (Amaranthus tricolor L.), planting media in the form of a mixture of soil and manure and alcohol, safranin, acetone. Med line, poerslen cup, spectrophotometer, and microscope were used in this study. The parameters measured plant height, number of leaves, leaf color, root length, number of roots, wet weight, dry weight, chlorophyll content, root epidermis thickness, root cortex thickness, and root stele diameter. The collected data then were analyzed by ANOVA test followed by DMRT 95\% confidence level using the SPSS 15 program. The results obtained showed that the addition of $\mathrm{NaCl}$ caused a decrease in spinach plant growth including plant height, the number of leaves, chlorophyll content, the ratio of the crown to root and decreased diameter of root stele. Plant growth decreases with increasing $\mathrm{NaCl}$ concentration since $\mathrm{NaCl}$ causes osmotic stress. This stress inhibits the absorption of water and nutrients needed by plants for metabolic processes.
\end{abstract} Keywords: Amaranthus tricolor, $\mathrm{NaCl}$, growth, roots 
Respons Fisiologis dan Anatomi Akar Tanaman Bayam (Prabowo, I. \& Rachmawati, D.)

\section{PENDAHULUAN}

Adanya cekaman garam menjadi salah satu kendala dalam pengelolaan lahan marginal. Cekaman garam merupakan kondisi dimana garam dapat larut dalam jumlah yang berlebih dan berakibat buruk bagi pertubuhan tanaman (Syakir, Nur, \& Januwati, 2008). Pengolahan irigasi dan drainase yang buruk pada lahan marginal dalam jangka waktu yang panjang dapat mengakibatkan hilangnya kesuburan tanah secara permanen (Staples \& Toenniessen, 1984).

Pada umumnya, petani jarang memperhatikan adanya cekaman salinitas di lingkungan pertanian mereka. Selain itu, dampak dari cekaman tersebut juga kurang diperhatikan sehingga secara tidak sadar terjadi penurunan produktivitas pertanian. Dalam bidang pertanian, cekaman garam menjadi hal yang perlu diperhatikan guna meningkatkan produktivitas tanaman. Akumulasi garam di tanah dapat menyebabkan gangguan fisiologis tanaman. Adanya penurunan pertumbuhan dapat disebabkan oleh efek salinitas terhadap satu atau beberapa faktor fisiologis (Omami, 2005, p. 188). Penelitian pengaruh cekaman $\mathrm{NaCl}$ terhadap tanaman bayam (Amaranthus tricolor L.) dilakukan untuk mengetahui seberapa jauh dampak dari cekaman $\mathrm{NaCl}$ terhadap pertumbuhan tanaman bayam sehingga di masa depan dapat dilakukan upaya perawatan optimum guna meningkatkan produktivitas tanaman.

Cekaman salinitas dapat mempengaruhi berbagai proses fisiologis dan biokimia diantaranya menyebabkan toksisitas ion dan cekaman air. Adanya garam terlarut dalam tanah seperti $\mathrm{NaCl}, \mathrm{Na}_{2} \mathrm{SO}_{4}, \mathrm{MgSO}_{4}, \mathrm{CaSO}_{4}$, $\mathrm{KCl}, \mathrm{MgCl}_{2}, \mathrm{Na}_{2} \mathrm{CO}_{3}$ dapat menyebabkan terjadinya cekaman salinitas (Tavakkoli, Rengasamy, \& McDonald, 2010). Di antara garam tersebut, $\mathrm{NaCl}$ merupakan enis garam yang paling mudah larut di dalam tanah. Tanah diklasifikasikan salin apabila memiliki Ece minimal $4 \mathrm{dS} / \mathrm{m}$ atau setara dengan $40 \mathrm{mM}$ $\mathrm{NaCl}$ (Munns \& Tester, 2008). Berbagai jenis garam memberikan tingkat salinitas yang berbeda- beda, diantaranya adalah garam klorida, garam sulfat dan garam bikarbonat dari natrium, kalsium dan magnesium. Natrium klorida $(\mathrm{NaCl})$ merupakan jenis garam yang dominan di daerah pantai (Syakir dkk., 2008). Kandungan natrium dalam $\mathrm{NaCl}$ berperan sebagai unsur hara fungsional bagi tumbuhan yang fungsinya menjaga keseimbangan turgor (Marschner, Kandeler, $\&$ Marschner 2003).

Adanya cekaman salinitas dapat menurunkan laju fotosintesis tanaman. Penurunan laju fotosintesis disebabkan karena rendahnya konsentrasi $\mathrm{CO}_{2}$ dalam kloroplas sehingga terjadi penurunan fiksasi $\mathrm{CO}_{2}$ yang menyebabkan penurunan reduksi karbon pada siklus calvin dan oksidasi $\mathrm{NADP}^{+}$ 
yang berfungsi sebagai penerima elektron terakhir pada proses fotosintesis. Adanya cekaman salinitas dapat menyebabkan penurunan tinggi tanaman, jumlah daun, dan luas per-mukaan daun tanaman Vicia faba (Qados, 2011). Selain itu, peningkatan $\mathrm{NaCl}$ juga dapat menmicu penutupan stomata, menurunkan kadar klorofil total pada daun, menurunkan laju fotosintesis dan biomassa pada tanaman jagung (Turan, Elkarim, Taban, \& Taban, 2009).

Permasalahan dari penelitian ini adalah bagaimana pengaruh cekaman $\mathrm{NaCl}$ terhadap pertumbuhan, kadar klorofil serta anatomi akar tanaman bayam (Amaranthus tricolor L.) serta pada konsentrasi berapa $\mathrm{NaCl}$ memberikan dampak negatif terhadap pertumbuhan tanaman bayam (Amaranthus tricolor L.). Tujuan dari penelitian ini adalah untuk mengetahui pengaruh cekaman $\mathrm{NaCl}$ terhadap pertumbuhan, kadar klorofil dan anatomi akar tanaman bayam (Amaranthus tricolor L.) serta mengetahui konsentrasi $\mathrm{NaCl}$ yang paling memberikan dampak buruk bagi pertumbuhan tanaman bayam (Amaranthus tricolor L.).

\section{METODE PENELITIAN}

Bahan yang digunakan dalam penelitian ini meliputi tanaman bayam (Amaranthus tricolor L.) dan $\mathrm{NaCl}$ berbagai konsentrasi (200, 400, 600, dan $800 \mathrm{mM})$. Media tanam berupa campuran tanah dan pupuk kandang dengan perbandingan 3:1. Campuran media tanam yang digunakan sebanyak $2 \mathrm{~kg}$. Alkohol $70 \%$ digunakan untuk sterilisasi, safranin $1 \%$ digunakan untuk mewarnai preparat, dan aseton $80 \%$ digunakan sebagai pelarut.

Alat yang digunakan adalah med line untuk mengukur tinggi tanaman dan panjang akar, oven digunakan untuk mengeringkan tanaman, timbangan digital untuk menimbang serbuk $\mathrm{NaCl}$, berat kering dan berat basah tanaman. Cawan poerslen digunakan untuk menghaluskan daun, kertas saring digunakan untuk menyaring filtrat dan spektrofotometer digunakan untuk mengukur absorbansi. Silet digunakan untuk memotong akar tanaman, gelas benda dan gelas penutup digunakan sebagai media untuk pengamatan menggunakan mikoskop. Gelas ukur untuk membuat larutan, botol flakon sebagai tempat untuk pengawetan. Mikroskop dan optilab digunakan untuk mengamati preparat yang telah dibuat.

Benih banyak yang berumur 14 hari dipindah tanam ke dalam polybag ukuran $25 \times 25 \mathrm{~cm}$ yang telah diisi campuran media tanam sebanyak $2 \mathrm{~kg}$ dan diaklimatisasi selama 2 hari. Perlakuan $\mathrm{NaCl}$ diberikan tiap 2 hari sekali selama 8 kali sebanyak $150 \mathrm{ml}$ untuk sekali perlakuan. Pengukuran tinggi tanaman dan jumlah daun dilakukan setiap 2 hari sekali. Pengukuran jumlah akar, panjang akar, kadar klorofil, berat basah dan berat 
kering tanaman dilakukan setelah tanaman berumur 32 hari. Pengukuran kadar klorofil dilakukan dengan spektrofotometer. Daun ketiga dari ujung batang dipetik kemudian ditimbang seberat 1 gr kemudian digerus dengan cawan porselin dan ditambahkan pelarut aseton $80 \%$ sebanyak $10 \mathrm{ml}$. selanjutnya larutan disaring dengan kertas saring. Filtrat yang diperoleh dimasukkan ke dalam kuvet kemudian diukur nilai absorbansinya dengan spektrofotometer panjang gelombang 646nm dan 663nm. Setelah diperoleh nilai absorbansi, kandungan klorofil dihitung dengan rumus:

$\begin{aligned} \text { Klorofil a }= & (12,21 \times \mathrm{A} .663)- \\ & (2,81 \times \mathrm{A} .646) \\ \text { Klorofil b }= & (20,13 \times \mathrm{A} .646)-\end{aligned}$

$$
(5,03 \times \mathrm{A} .663)
$$

Klorofil Total $(\mathrm{mg} / \mathrm{L})=(17,3 \times$ A.646) +

$$
\text { (7,18 x A.663) }
$$

Kadar klorofil yang terukur selanjutnya dikonversi ke dalam satuan $\mathrm{mg} / \mathrm{ml}$ dengan rumus (Harborne, 1978) berikut.

$$
\frac{\frac{10}{1000} \times \text { kadar klorofil }}{0,1}
$$

Pengamatan anatomi akar dilakukan dengan membuat preparat semi permanen dengan metode free hand section. Akar dipotong sepanjang $1 \mathrm{~cm}$ mulai dari ujung akar. Organ akar diiris melintang menggunakan silet. Hasil irisan ditampung pada wadah yang berisi alkohol $70 \%$. Penyortiran irisan organ akar dilakukan dengan menggunakan mikroskop. Irisan organ akar yang telah diseleksi kemudian diwarnai dengan pewarna safranin $1 \%$ dalam alkohol $70 \%$. Irisan yang telah terwarnai diletakkan di atas gelas benda kemudian diberi gliserin murni dan ditutup dengan gelas penutup kemudian diamati dengan mikroskop yang telah terhubung dengan optilab. Setelah dilakukan pengamatan, irisan disimpan di dalam botol flakon yang berisi campuran alkohol $70 \%$ dan safranin untuk pengawetan. Parameter yang diukur adalah tebal epidermis, tebal korteks dan diameter stele. Data yang diperoleh dianalisis dengan uji ANOVA, jika hasil analisis menunjukkan berbeda nyata maka akan dilanjutkan dengan uji DMRT pada taraf kepercayaan 95\% dengan menggunakan program SPSS versi 15.

\section{HASIL DAN PEMBAHASAN}

Penelitian ini mempelajari pengaruh cekaman $\mathrm{NaCl}$ dengan berbagai konsentrasi $(0,200,400,600$, dan $800 \mathrm{mM})$ terhadap pertumbuhan dan anatomi akar tanaman bayam (Amaranthustricolor L.). Pengamatan pertumbuhan meliputi tinggi tanaman dan jumlah daun dilakukan setiap dua hari sekali selama delapan kali. Sedangkan parameter jumlah akar, panjang akar, berat basah, berat kering, dan kadar klorofil dilakukan pada saat tanaman berumur 32 hari.

Tingginya konsentrasi $\mathrm{NaCl}$ dan rendahnya potensial air dapat menyebabkan 
stres osmotik pada tanaman, selain itu meningkatnya akumulasi ion $\mathrm{Na}$ dan $\mathrm{Cl}$ dapat menyebabkan toksisitas pada tanaman. Hasil penelitian menunjukkan terjadinya penurunan tinggi tanaman seiring dengan peningkatan konsentrasi $\mathrm{NaCl}$ dan pada Tabel 1, konsentrasi $\mathrm{NaCl} 800 \mathrm{mM}$ menunjukkan hasil penurunan tinggi tanaman yang signifikan yaitu $20,70 \mathrm{~cm}$ dibandingkan dengan kontrol dengan tinggi 32,02 cm. pada parameter jumlah daun terjadi penurunan seiring dengan meningkatnya konsentrasi $\mathrm{NaCl}$. Pada konsentrasi 600 dan $800 \mathrm{mM}$ menunjukkan hasil yang signifikan. Tanaman dapat mengatasi cekaman salinitas salah satunya dengan meminimalisir penggunaan air dan menjaga tekanan turgor dengan tujuan untuk mencegah berbagai kerusakan akibat munculnya ROS. Produksi ROS dapat dipicu dengan tingginya konsentrasi ion Na. Selain itu tanaman juga dapat mensintesis beberapa enzim dan senyawa non enzim yang berperan dalam mencegah terjadinya efek sitotoksisitas
ROS. Senyawa enzim yang dihasilkan di antaranya superoxide dismutase, ascorbate peroxidase, glutathione reductase, catalase, dan peroxidase. Senyawa nonenzim yang dihasilkan di antaranya glutathione, asam askorbat, karotenoid, dan flavonoid yang mampu menjaga keseimbangan ROS di dalam sel (Chutipajit, Cha-Um, \& Sompornpailin, 2009).

Tanaman berusaha bertahan hidup dengan memaksimalkan pertumbuhan akar untuk meningkatkan penyerapan air guna menyeimbangkan tekanan turgor. Hal tersebut dapat dilihat pada Tabel 2 bahwa pada konsentrasi 200 hingga 800 $\mathrm{mM}$ terjadi kenaikan jumlah akar, untuk hasil panjang akar tidak menunjukkan nilai yang berbeda jauh. Adanya cekaman $\mathrm{NaCl}$ dapat menyebabkan tanaman lebih banyak mendistribusikan fotosintat ke dalam akar guna memaksimalkan penyerapan hara dan air. Penurunan laju fotosintesis berdampak pada penurunan biomasa tanaman, semakin

Tabel 1

Pengaruh $\mathrm{NaCl}$ terhadap Pertumbuhan Tanaman Bayam (Amaranthus tricolor L.) Umur 32 Hari

\begin{tabular}{ccccc}
\hline Perlakuan & $\begin{array}{c}\text { Tinggi Tanaman } \\
(\mathrm{cm})\end{array}$ & $\begin{array}{c}\text { Jumlah Daun } \\
(\text { helai) }\end{array}$ & $\begin{array}{c}\text { Berat Basah } \\
\text { Total }(\mathrm{g})\end{array}$ & $\begin{array}{c}\text { Berat Kering } \\
\text { Total }(\mathrm{g})\end{array}$ \\
\hline $\mathrm{NaCl} 0 \mathrm{mM}$ & $32,02^{\mathrm{a}}$ & $9,00^{\mathrm{a}}$ & $5,44^{\mathrm{a}}$ & $0,36^{\mathrm{a}}$ \\
$\mathrm{NaCl} 200 \mathrm{mM}$ & $30,36^{\mathrm{a}}$ & $8,00^{\mathrm{ab}}$ & $4,91^{\mathrm{ab}}$ & $0,29^{\mathrm{a}}$ \\
$\mathrm{NaCl} 400 \mathrm{mM}$ & $29,12^{\mathrm{a}}$ & $7,00^{\mathrm{abc}}$ & $4,77^{\mathrm{ab}}$ & $0,29^{\mathrm{a}}$ \\
$\mathrm{NaCl} 600 \mathrm{mM}$ & $25,14^{\mathrm{ab}}$ & $6,00^{\mathrm{bc}}$ & $3,34^{\mathrm{ab}}$ & $0,22^{\mathrm{a}}$ \\
$\mathrm{NaCl} 800 \mathrm{mM}$ & $20,70^{\mathrm{b}}$ & $5,00^{\mathrm{c}}$ & $2,50^{\mathrm{b}}$ & $0,21^{\mathrm{a}}$ \\
\hline
\end{tabular}

Keterangan: Angka yang diikuti huruf yang sama pada satu kolom menunjukkan tidak berbeda nyata dengan uji DMRT taraf kepercayaan 95\%. 
Respons Fisiologis dan Anatomi Akar Tanaman Bayam (Prabowo, I. \& Rachmawati, D.)

Tabel 2

Pengaruh NaCl terhadap Panjang dan Jumlah Akar

Tanaman Bayam (Amaranthus tricolor L.) Umur 32

Hari

\begin{tabular}{lcc}
\hline Perlakuan & $\begin{array}{c}\text { Panjang Akar } \\
(\mathrm{cm})\end{array}$ & $\begin{array}{c}\text { Jumlah Akar } \\
\text { (buah) }\end{array}$ \\
\hline $\mathrm{NaCl} 0 \mathrm{mM}$ & $18,04^{\mathrm{a}}$ & $19,60^{\mathrm{a}}$ \\
$\mathrm{NaCl} 200 \mathrm{mM}$ & $16,66^{\mathrm{a}}$ & $12,60^{\mathrm{a}}$ \\
$\mathrm{NaCl} 400 \mathrm{mM}$ & $18,08^{\mathrm{a}}$ & $15,00^{\mathrm{a}}$ \\
$\mathrm{NaCl} 600 \mathrm{mM}$ & $16,24^{\mathrm{a}}$ & $17,00^{\mathrm{a}}$ \\
$\mathrm{NaCl} 800 \mathrm{mM}$ & $17,26^{\mathrm{a}}$ & $19,20^{\mathrm{a}}$ \\
\hline
\end{tabular}

Keterangan: Angka yang diikuti huruf yang sama pada satu kolom menunjukkan tidak berbeda nyata dengan uji DMRT taraf kepercayaan 95\%.

rendah laju fotosintesis maka semakin rendah biomasa tanaman yang dibuktikan dengan menurunnya berat basah dan kering tanaman. Penurunan biomasa tanaman juga dapat disebabkan karena tanaman menyintesis hormon ABA sebagai mekanisme pertahanan diri terhadap cekaman. Hormon ABA disintesisi di akar dan di-transport ke daun sehingga stomata menutup dan difusi $\mathrm{CO}_{2}$ terhambat sehingga berdampak pada laju fotosintesis dan distribusi fotosintat mengalami penurunan.

Cekaman garam tinggi menyebabkan penurunan jumlah air dan unsur hara pada tanaman yang akan menghambat proses fotosintesis. Penurunan unsur hara dan fotosintatakan berdampak pada kadarklorofil. Tabel 3 menunjukkan bahwa kenaikan konsentrasi $\mathrm{NaCl}$ dapat menurunkan kadar klorofil baik klorofil a, klorofil b maupun klorofil total tanaman bayam. Pada parameter kadar klorofil total, konsentrasi 600 dan 800 $\mathrm{mM}$ menunjukkan hasil yang berbeda nyata yaitu sebesar $0.742 \mathrm{mg} / \mathrm{ml}$ dan $0,718 \mathrm{mg}$ / $\mathrm{ml}$ dibandingkan konsentrasi $0 \mathrm{mM}$ yaitu sebesar 1,111 mg/ml. Hasil perhitungan klorofil a dan klorofil b juga menunjukkan hasil yang sama bahwa konsentrasi $\mathrm{NaCl} 600$ dan $800 \mathrm{mM}$ memberikan nilai yang berbeda nyata dengan perlakuan kontrol berdasarkan uji statistik. Penurunan kadar klorofil dapat terjadi karena kerusakan membran (Djanaguiraman, Sheeba, Shanker, Devi, \& Bangarusamy, 2006). Selain itu, penurunan kadar klorofil dapat terjadi karena gangguan fungsi seluler dan kerusakan rantai transport elektron pada fotosintesis akibat akumulasi ion (Croser, Renault, Franklin, \& Zwiazek, 2001).

Pada parameter diameter stele menunjukkan adanya penurunan nilai seiring dengan peningkatan konsentrasi $\mathrm{NaCl}$. 
Jurnal Penelitian Saintek, Vol. 25, Nomor 1, 2020

Tabel 3

Pengaruh NaCl terhadap Kadar Klorofil Tanaman Bayam (Amaranthus tricolor L.) Umur 32 Hari

\begin{tabular}{lccc}
\hline Perlakuan & $\begin{array}{c}\text { Klorofil a } \\
(\mathrm{mg} / \mathrm{ml})\end{array}$ & $\begin{array}{c}\text { Klorofil b } \\
(\mathrm{mg} / \mathrm{ml})\end{array}$ & $\begin{array}{c}\text { Klorofil Total } \\
(\mathrm{mg} / \mathrm{ml})\end{array}$ \\
\hline $\mathrm{NaCl} 0 \mathrm{mM} \mathrm{0}$ & $710^{\mathrm{a}} 0$ & $402^{\mathrm{a}} 1$ & $111^{\mathrm{a}}$ \\
$\mathrm{NaCl} 200 \mathrm{mM} \mathrm{0}$ & $632^{\mathrm{ab}} 0$ & $364^{\mathrm{ab}} 0$ & $994^{\mathrm{ab}}$ \\
$\mathrm{NaCl} 400 \mathrm{mM} \mathrm{0}$ & $604^{\mathrm{ab}} 0$ & $348^{\mathrm{ab}} 0$ & $950^{\mathrm{ab}}$ \\
$\mathrm{NaCl} 600 \mathrm{mM} \mathrm{0}$ & $486^{\mathrm{b}} 0$ & $262^{\mathrm{bc}} 0$ & $742^{\mathrm{b}}$ \\
$\mathrm{NaCl} 800 \mathrm{mM} \mathrm{0}$ & $482^{\mathrm{b}} 0$ & $234^{\mathrm{c}} 0$ & $718^{\mathrm{b}}$ \\
\hline
\end{tabular}

Tabel 4

Pengaruh $\mathrm{NaCl}$ terhadap Tebal Epidermis, Kotrels dan Diameter Stele

Tanaman Bayam (Amaranthus tricolor L.) Umur 32 Hari

\begin{tabular}{llll}
\hline \multicolumn{1}{c}{ Perlakuan } & $\begin{array}{c}\text { Tebal Epidermis } \\
(\mu \mathrm{m})\end{array}$ & $\begin{array}{c}\text { Tebal Korteks } \\
(\mu \mathrm{m})\end{array}$ & $\begin{array}{c}\text { Diameter Stele } \\
(\mu \mathrm{m})\end{array}$ \\
\hline $\mathrm{NaCl} 0 \mathrm{mM} \mathrm{42}$ & $91^{\mathrm{b}} 219$ & $34^{\mathrm{a}} 2633$ & $43^{\mathrm{a}}$ \\
$\mathrm{NaCl} 200 \mathrm{mM} 45$ & $40^{\mathrm{b}} 201$ & $28^{\mathrm{a}} 2663$ & $08^{\mathrm{a}}$ \\
$\mathrm{NaCl} 400 \mathrm{mM} 55$ & $56^{\mathrm{a}} 239$ & $49^{\mathrm{a}} 2439$ & $79^{\mathrm{a}}$ \\
$\mathrm{NaCl} 600 \mathrm{mM} 43$ & $75^{\mathrm{b}} 212$ & $51^{\mathrm{a}} 2138$ & $56^{\mathrm{a}}$ \\
$\mathrm{NaCl} 800 \mathrm{mM} 42$ & $56^{\mathrm{b}} 195$ & $72^{\mathrm{a}} 1734$ & $01^{\mathrm{a}}$ \\
\hline
\end{tabular}

Keterangan: Angka yang diikuti huruf yang sama pada satu kolom menunjukkan tidak berbeda nyata dengan uji DMRT taraf kepercayaan 95\%.

Berdasarkan Tabel 4, konsentrasi $\mathrm{NaCl}$ $200 \mathrm{mM}$ memberikan hasil yang paling tinggi yaitu 2.663,08 $\mu \mathrm{m}$, nilai tersebut tidak berbeda jauh dengan konsentrasi $0 \mathrm{mM}$ yaitu 2.633,43 $\mu \mathrm{m}$. Sedangkan mulai konsentrasi 400 hingga $800 \mathrm{mM}$ menunjukkan penurunan yang cukup tinggi walaupun berdasarkan uji statistik tidak menunjukkan hasil yang berbeda nyata. Sinaga (2007) menjelaskan adanya peningkatan diameter stele berarti meningkatkan kemampuan tanaman untuk mengabsorbsi air dan zat hara yang dibawa ke daun untuk metabolismenya. Peningkatan diameter stele diikuti dengan penambahan jumlah xilem akar, diameter xilem, dan konduktivitas akar.

\section{SIMPULAN}

Berdasarkan hasil dan pembahasan dapat disimpulkan bahwa pertama, adanya cekaman $\mathrm{NaCl}$ dapat menyebabkan penurunan pertumbuhan tanaman bayam (Amaranthus tricolor L.). Kedua, adanya cekaman $\mathrm{NaCl}$ dapat menurunkan kadar klorofil dan rasio tajuk banding akar 
tanaman bayam (Amaranthus tricolor L.). Ketiga, konsentrasi $\mathrm{NaCl} 600$ dan $800 \mathrm{mM}$ memberikan nilai penurunan yang signifikan terhadap pertumbuhan dan diameter stele akar tanaman bayam (Amaranthus tricolor L.).

\section{DAFTAR PUSTAKA}

Chutipaijit, S., Cha-Um, S., \& Sompornpailin, K. (2009). Differential accumulations of proline and flavonoids in indica rice varieties against salinity. Pak. $J$. Bot, 41(5), 2497-2506.

Croser, C., Renault, S., Franklin, J., \& Zwiazek, J. (2001). The effect of salinity on the emergence and seedling growth of Picea mariana, Picea glauca, and Pinus banksiana. Environmental Pollution, 115(1), 9-16.

Djanaguiraman, M., Sheeba, J. A., Shanker, A. K., Devi, D. D., \& Bangarusamy, U. (2006). Rice can acclimate to lethal level of salinity by pretreatment with sublethal level of salinity through osmotic adjustment. Plant Soil, 284, 363-373.

Marschner, P., Kandeler, E., \& Marschner, B. (2003) Structure and function of the soil microbial community in a longterm fertilizer experiment. Soil Biology and Biochemistry, 35, 453-461.

Munns, R., \& Tester, M. (2008). Mechanisms of salinity tolerance. Annual Review of Plant Biology, 59, 651-681.
Omami, E. N. (2005). Response of amaranth to salinity stress (Dissertation unpublish report). Department of Plant Production and Soil Science, Faculty of Natural and Agricultural Sciences, University of Pretoria.

Qados, A. M. A. (2011). Effect of salt stress on plant growth and metabolism of bean plant Vicia faba (L.). Journal of the Saudi Society of Agricultural Sciences, 10(1), 7-15.

Sinaga, R. (2007). Analisis metode ketahanan rumput gajah dan raja akibat cekaman kekeringan berdasarkan respons anatomi akar dan daun. Jurnal Biologi Sumatre, 2(1), 17-20.

Staples, R. C., \& Toenniessen, G. H (1984). Salinity tolerance in plants. New York: John Wiley \& Sons.

Syakir, M., Nur, M., \& Januwati, M. (2008). Pengaruh salinasi terhadap pertumbuhan, produksi dan mutu sambiloto (Andrographis paniculate nees). Buletin Littro, 19(2), 129-137.

Tavakkoli, E., Rengasamy, P., \& McDonald, G. K. (2010). High concentrations of $\mathrm{Na}+$ and $\mathrm{Cl}-$ ions in soil solution have simultaneous detrimental effects on growth of faba bean under salinity stress. Journal of Experimental Botany, 61(15), 4449-4459.

Turan, M. A., Elkarim, A. H. A., Taban, N., \& Taban, S. (2009). Effect os salt stress on growth, stomatal resistance, proline and chlorophyll concentrations on maize plant. African Journal of Agricultural Research, 4(9), 893-897. 